\title{
Free Zone Scientology and Other Movement Milieus: A Preliminary Characterization
}

\author{
JAMES R. LEWIS \\ The University of Tromsø
}

\begin{abstract}
Free Zone refers to the subculture constituted by people and organizations that adhere to the beliefs and practices of Scientology but who do so outside of - and without the sanction of - the Church of Scientology. The analysis in the present article uses the Free Zone plus a selection of comparable subcultures associated with other religious groups as case studies to explore the nature and structure of movement milieus. The notion of a movement milieu is derived from Colin Campbell's influential formulation, though certain significant features of movement milieus serve to distinguish them from - and to make them more than simply subsets of - the cultic milieu.
\end{abstract}

Keywords: Schism, Cultic Milieu, New Religious Movements, Social Movements, Scientology

Colin Campbell's 'The Cult, Secularization and the Cultic Milieu' was originally published over forty years ago. This essay quickly became a classic article, often cited in analyses of the alternative spiritual subculture that was later referred to as the New Age movement. However, the 'New Age' label never fully supplanted 'cultic milieu' (Passamai 2007), nor have more nuanced notions, such as Chris Partridge's 'occulture' (2006). Part of the attractiveness of Campbell's notion was the emphasis he placed on the milieu as a kind of fertile socio-cultural 'soup', out of which new organizations emerged, only to quickly lose their vitality and dissolve back into the milieu while simultaneously contributing elements to yet newer groups.

Given that cultic groups have a tendency to be ephemeral and highly unstable, it is a fact that new ones are being born just as fast as the old ones die. There is a continual process of cult formation and collapse which parallels the high turnover of membership at the individual level. Clearly, therefore, cults must exist within a milieu which, if not conducive to the maintenance of individual cults, is clearly highly conducive to the spawning of cults in general. Such a generally supportive cultic milieu is continually giving birth to new cults, absorbing the debris of the dead ones and creating new 
generations of cult-prone individuals to maintain the high levels of membership turnover. Thus, whereas cults are by definition a largely transitory phenomenon, the cultic milieu is, by contrast, a constant feature of society. It could therefore prove more viable and illuminating to take the cultic milieu and not the individual cult as the focus of sociological concern. (Campbell 2002 [1972], 14.)

Another analytic term that Campbell's article helped to popularize was the notion of seekership. Thus, in addition to the particular new religions which emerge out of the milieu, this subculture is constituted by a larger population of seekers who, in John Lofland and Rodney Stark's words, are 'searching for some satisfactory system of religious meaning to interpret and resolve their discontents' $(1965,868)$. By implication, these individuals have adopted lifestyles that prioritize seeking over finding, leading them to become temporarily affiliated with one group after another, in a pattern that has been referred to as a 'conversion career' (Richardson 1978; 1980). This pattern of seeking simultaneously contributes, on the one hand, to the fluidity of the cultic milieu's contents and, on the other, to the continuity of the milieu's deep structure.

One contrasting term to cult is sect. In the early twentieth century, the consensus among sociologists of religion was that (as in Campbell's discussion above) cults were small ephemeral groups that developed outside of the Judeo-Christian mainstream. Sects, on the other hand, were typically Protestant groups that had broken away from earlier churches in a quest for stricter and more intense forms of spirituality, somewhat withdrawn from participation in mainstream culture. Though this distinction has been thoroughly criticized and various reformulations offered (e.g., Wallis 1976; 1979), it has not been entirely abandoned.

Perhaps because sects were earlier portrayed as schisms from mainstream churches, no one seems to have given thought to the possibility of the parallel phenomenon of a Protestant 'sectarian milieu', or at least not as a milieu out of which new groups emerged. ${ }^{1}$ If, however, we focus on the subculture constituted by conservative Protestant bodies rather than on their imputed status as schismatics from mainstream Protestantism, it immediately becomes obvious that there exists a reasonably well-defined Evangelical/Pentecostal milieu which extends well beyond specific church bodies to include members of other conservative churches, as well as home

1 The expression 'sectarian milieu' has, however, been used to analyze certain phenomena in other religious contexts (e.g., Seiwert 2003;Wansbrough 2006 [1978]). 
church members and unaffiliated individual Christians who often intermingle comfortably in such venues as Christian bookstores, Christian rock concerts and the like. (There are, nevertheless, certain groups considered beyond the pale, such as the Jehovah's Witnesses and Mormons.)

Similar to the 'overlapping communication structures' which Campbell noted were characteristic of the cultic milieu (Campbell 2002, 15), the Evangelical/Pentecostal world is supported by its own system of magazines, publishers, bookstores, social gatherings and other communication networks. It should also be obvious with a little reflection that far more new churches emerge out of schisms from other conservative churches within this milieu than are generated by schisms from mainstream churches. In other words, if we focus on certain defining characteristics of his formulation and ignore others, it is easy enough to perceive a conservative Protestant milieu roughly comparable to Campbell's cultic milieu.

\section{Movement Milieus}

The existence of a conservative Protestant milieu is clear enough. However, it is possible to expand Campbell's fertile notion further and to identify yet other subcultural realms. In some cases, these constitute subsets of the cultic milieu; in other cases, they do not. One of the first more-than-casual extensions of this notion to other topics is Jesper Aagaard Petersen's discussion of the Satanic milieu, which is 'located' partly within and partly outside the broader cultic milieu - a 'cult-producing substance of key terms and practices as well as a reservoir of ideas' relating to 'the satanic' $(2009,223)$.

Far from exhibiting the open-minded, mutually tolerant characteristics of the cultic milieu, the Satanic milieu is anything but. Furthermore, and also unlike the cultic milieu, the Satanic milieu is highly contentious and schismatic. As Petersen discusses, 'Satanism thrives on both formulations of positive content and negative deviance and tension in order to produce a coherent identity on the individual and collective level. In this sense Satanism differs little when compared to other religious trends of this type - innovations and schisms are the norm.' (Petersen 2009, 219.)

One issue raised by the example of Satanism that Petersen does not explicitly discuss is that while schisms may weaken specific organizations, they can contribute to the expansion and thus the strengthening of a particular subculture - in this case, to the expansion of the Satanic milieu. Satanism as a religious self-identity initially came into existence as a consequence of the creative activity of Anton LaVey and his relatively tiny Church of 
Satan, but later Satanism evolved into a significantly larger decentralized subculture. Similar observations apply to milieus that have arisen in the wake of certain other movements.

I will henceforth refer to these emergent milieus as movement milieus, using movement as a generic term to indicate an identifiable subculture. I will also refer to the original group out of which such a milieu arises as the primary body or, more simply, as the primary. I am borrowing this term from astronomy, where a celestial body around which other bodies orbit is called the primary, and orbiting bodies called satellites or secondary bodies. Thus, for example, the Earth is the primary in relationship to the Moon (the Earth's satellite), whereas the Sun is the primary in relationship to the Earth (one of the Sun's satellites). In other words, a movement milieu is a bit like a solar system in the sense that it has a primary body around which the rest of the milieu revolves - though I should quickly add that in smaller milieus, secondary bodies consist predominantly or entirely of lose associations of individuals rather than of other organizations. This is a characteristic that distinguishes movement milieus from the cultic milieu, which does not have a primary. In the balance of this article, I will use secondary rather than satellite because of other connotations associated with the latter term.

In the case of the original Satanic milieu, Anton LaVey's Church of Satan was the primary. However, as this milieu developed, it became progressively less dependent on its primary so that - with the exception of groups and individuals directly in the Church of Satan's line of influence - the parameters of the current 'post-Satanic' milieu are no longer defined by LaVey's ideas. Many contemporary groups simply ignore the Church of Satan rather than base their legitimacy on LaVey's work or person. On this specific point, the current Satanic milieu has developed a decentralized structure that in some ways approaches the form of the contemporary sectarian Protestant milieu.

If one wanted to postulate a Protestant (in the largest sense) milieu - a notion that would conceivably be useful for certain kinds of analyses - the primary body would be the Catholic Church. However, the contemporary Evangelical/Pentecostal milieu came into being as the result of a traditionalist reaction to Christian modernism, meaning there is no single religious body to play the role of a primary. On this particular point, the Protestant sectarian milieu is closer to the cultic milieu than most of the subcultures I am here referring to as movement milieus.

As the example of the Protestant sectarian milieu indicates, the movement milieu pattern is not confined to contemporary new religions. Anyone familiar with Salt Lake City, for instance, is aware of the city's Mormon 
milieu. We can also cautiously project this notion back in time to, for example, what might be termed the mystery religion milieu in the large cities of the Hellenistic period. Like the Hindu guru milieu discussed below, a significant religious subculture of this period was constituted by a complex assortment of different religious bodies, particularly but not exclusively mystery religions associated with the worship of Isis, Cybele and other deities. A more fundamental primary body that set the parameters for the entire milieu was lacking. At the same time, the mystery religions were relatively stable structures within the milieu, a characteristic that makes Hellenistic religious culture more than simply an ancient version of the cultic milieu.

Finally, one can sometimes find similar patterns in certain social movements. Thus, for example, I vividly recall the fractious new left movement of the sixties and early seventies, out of which emerged an entire subculture of hard core leftists, marginally involved participants, self-described radical artists, radical writers and a variety of ideologically-linked political organizations that, as lampooned in Monty Python's The Life of Brian, seemed more passionate about attacking each other than in bringing down the establishment.

\section{Sacred Schisms}

The present analysis arises in part out of a current research project on Scientology and in part out of a close reading of Sacred Schisms: How Religions Divide (Lewis \& Lewis 2009). In his contribution to Sacred Schisms, 'Schism and Consolidation: The Case of the Theosophical Movement', Olav Hammer uses the suggestive expression 'schismatic milieu' to refer to a particularly schism-prone tradition, the Theosophical Society and its splinter groups. Drawing on the plentiful history of organizational splits within Theosophy for illustrations, his analysis focuses on the identity politics that take place as new schisms seek to distinguish themselves from their parent body while maintaining enough of a family resemblance with the original organization to seem familiar - and, more importantly, legitimate - in the eyes of potential converts. Hammer discusses the forging of new groups in terms of the branding of distinctive new religious products (Hammer 2009, 200-1).

My earlier observation about how schisms might weaken specific organizations but might also contribute to the strengthening and expansion of larger milieus was inspired by some of the chapters found in Sacred Schisms. One of these chapters, Murphy Pizza's 'Schism as Midwife', discusses the Neo-Pagan community in the Twin Cities (referred to by participants as 
Paganistan) in terms that resonate with Campbell's characterization of the cultic milieu. Like the Satanic milieu, contemporary Paganism is in some ways a sub-milieu within the cultic milieu which could be termed the Pagan milieu. Paganistan, in turn, constitutes a kind of 'sub-sub' milieu within Paganism. Pizza's chapter on schisms from the Wiccan Church of Minnesota (WicCoM) highlight what was implicit in Petersen's analysis, namely that, instead of viewing schisms as failures, schisms are instead 'a catalyst for growth and rethinking community rather than a failure of a church [and a] process in Paganistan's continual solidifying and growth' (Pizza 2009, 260). WicCoM also presents us with the interesting case of a secondary body that became the primary for the Pagan milieu in the Twin Cities. In other words, the primary for the larger Pagan milieu is usually regarded as Gerald Gardner's Wiccan lineage. WicCoM, then, is a secondary body with respect to Wicca and a primary for Paganistan.

Another insightful chapter in Sacred Schisms is E. Burke Rochford's 'Succession, Religious Switching, and Schism in the Hare Krishna Movement', in which the author recounts the many institutional woes and attendant dramas of schisms within the Hare Krishna Movement. He also points out that Hare Krishna schisms tend to be expressed in terms of the quest for doctrinal purity, but the underlying conflicts are often matters of contested religious authority. One consequence of these frequent conflicts is that many people who have defected from these warring organizations continue to participate in a larger Hare Krishna milieu that has developed outside of the institutional control of ISKCON (the International Society for Krishna Consciousness). As with Pizza's discussion of the Pagan milieu, Rochford argues that institutional failures are not the same as movement failures (Rochford 2009, 282).

Satanism, Paganism and Hare Krishna are, of course, quite different. Except for a short period in the early seventies during which the Church of Satan tried to establish enclaves in other cities, Satanism for the most part has been a decentralized, anarchistic movement that did not really come into its own until the advent of the Internet. As a consequence, the contemporary Satanic milieu is predominately an online milieu, with many self-identified Satanists considering Satanism to be a personal philosophy rather than a religion based on ritual and magical practices. In contrast, ISKCON has always been a practice-oriented religion, built around group worship at community temples. While one can currently find many exISKCON websites and online discussion groups, 'ISKCON members who left the organization during the turmoil of the 1980s and 1990s often moved 
into enclave communities surrounding ISKCON's temples' (Rochford 2009, 282). Thus the early Hare Krishna milieu forms a useful contrast to the Internet-based Satanic milieu, whereas the Pagan Milieu lies somewhere in between.

Cynthia Ann Humes's chapter, 'Schisms within Hindu Guru Groups', presents a somewhat different case study. Humes examines three distinct splinters from the Transcendental Meditation movement (TM). The largest of these, Ravi Shankar's Art of Living Foundation, remained nominally within the TM fold for many years, and is currently larger than the parent organization in terms of number of members. Another splinter was created when the popular author-lecturer Deepak Chopra was ejected from TM as a potential threat to the Maharishi's authority. Though a weak TM milieu constituted in part by non-affiliated TMers emerged in the vicinity of the Maharishi International University, TM differs markedly from the Hare Krishna Movement. Though a significant number of defectors from the TM organization later joined the Art of Living Foundation, many others subsequently became involved in other Hindu guru groups - groups that participate in what we might refer to as the Hindu guru milieu - that share basic beliefs with TM (in this regard refer, e.g., to Williamson 2010) but that differ in many specifics. Contrary to what one might expect, the TM brand simply did not stand out as being sharply distinct from other guru groups, which facilitated organizational switching outside of the 'gravitational field' of TM. ${ }^{2}$

The Church of Scientology (CoS) was not one of the groups covered in Sacred Schisms. Scientology grew out of the activities of L. Ron Hubbard (1911-1986), a successful author of popular fiction who initially founded Dianetics as a therapy-oriented movement. In the early days of Dianetics, Hubbard envisioned himself an empirical scientist rather than a religious leader. The transition from therapy to religion is reflected in the evolution of auditing. Dianetics auditing consists of an auditor guiding someone through

2 The ease or difficulty of organizational switching has regularly been discussed in terms of the 'conservation of cultural capital' notion (e.g., Stark 2003[1996]; Stark and Finke 2000, 121-3). In Rochford's words, 'people disaffiliating from a religious group are much more likely to join another that is similar to their original faith. In addition, more disciplined and demanding groups such as religious sects more often retain their members precisely because their unique religious identities limit possibilities for religious switching. [...] The North American context, devotees leaving ISKCON had next to no options available for religious switching, given the extreme uniqueness of their religious capital.' (2009, 282.) In sharp contrast, the religious capital of former TMers was much less unique. For instance, many ex-TMers became devotees of Amma, the so-called 'hugging guru' (Humes 2013). 
various mental processes in order to free the individual from certain kinds of traumatic memories in the subconscious. When the individual is freed from the effects of these memories, she or he is said to have achieved the state of Clear.

The higher levels of counselling that were developed within Scientology auditing deal with the Thetan - the individual soul - achieving a state of spiritual freedom referred to as Operating Thetan (usually abbreviated $O T$ ), which is the spiritual parallel to Clear. The Church's secret teachings, which are not revealed to students of Scientology until they reach the third OT level, are that what drags us down at the spiritual level are confused, disembodied souls from other planets who have attached themselves to us (Rothstein 2009). Hubbard's account of the source of these souls is part of what is commonly referred to as the space opera, though in its original sense space opera referred to a broader narrative. The task of Scientology auditing is a kind of exorcism in which these body thetans are 'cleared' from their connections to our souls. At its core, then, Scientology is, like its predecessor movement, still a therapeutically-oriented organization, and its central practice is Dianetics auditing writ large.

As the Church of Scientology developed, Hubbard separated himself from the day-to-day running of his organization and retreated into the background, surrounding himself with a small cadre of loyalists through whom he communicated with the rest of the organization. He stopped attending public events, chiefly because of legal problems. Toward the end of his life, only a handful of Scientologists even knew where Hubbard was physically located. The secretiveness of this situation provided fertile ground for later conspiracy theories about the usurpation of power that allegedly took place in the years leading up to his death.

\section{The Free Zone}

Free Zone refers to the large but loosely-organized community of people who consider themselves Scientologists, but not members of the Church of Scientology. Originally coined in 1984 by Bill Robertson - an early associate of Scientology's founder - the term is ultimately derived from Hubbard's space opera teachings. Across the course of the sixty years of the Church's existence (counting the Dianetics movement as part of Church history), tens of thousands of Scientologists left the fold. There have also been schisms and new alternative organizations, some of which were sued out of existence by the Church. 
Comparable to TM's ejection of Deepak Chopra, Hubbard also regularly sacked high-ranking Scientologists who he thought might one day challenge his authority (Wallis 1979, 154-5). One result of this pre-emptive policy - in combination with certain other ill-considered actions, such as the Mission Holders' Conference that led to the schism of $1982 / 3^{3}$ - was to place numerous highly-trained, upper level Scientologists outside of Church control. ${ }^{4}$

The emergence of the Internet within the past couple of decades has been a boon to the Free Zone. It has not only provided Freezoners with a forum for airing grievances, but the Internet has also provided more recent ex-members with points of contact for becoming affiliated with Free Zone organizations and for availing themselves of Scientology services and trainings that had formerly only been available through the Church. More generally, the Internet has become a key component in the majority of movement milieus, in part because it allows widely separated individuals to communicate with other participants in what are often quite small subcultures. ${ }^{5}$

The diversity among the various milieus mentioned earlier effectively frustrates attempts to examine any specific one as 'typical'. The Free Zone is nevertheless a useful case study for the purpose of understanding certain general characteristics of movement milieus. Thus, for example, primary organizations adopt a variety of attitudes toward former participants. In sharp contrast to other primaries, the Church of Scientology has unusually harsh policies regarding ex-members. For instance, if a former member has been declared a suppressive person (SP), individuals who had been personally close to her or him (e.g., family members, close friends, even a spouse) were required to cut off all communication. By, in effect, discouraging rapprochement with the primary organization, $\mathrm{CoS}^{\prime}$ s disconnection policy has contributed to the growth of the Free Zone.

The Free Zone has a particularly rich diversity of constituent elements. Even before Hubbard founded the Church of Scientology, many of the auditors he trained during the Dianetics phase of the movement had es-

3 Refer, e.g., to accounts of the conference in Atack 1990, part 7, Chapter 1; Rathbun 2013, Chapter 16 and in Townsend 1985, Chapter 13. It was the Mission Holders' Conference in combination with an internal Church shakeup that led to the emergence of Free Zone Scientology.

4 Thus, for example, following the Conference, '[v]irtually every major productive mission holder left the church over the next year or two....' (Rathbun 2013, 195).

5 The centrality of the Internet for allowing otherwise disconnected ex-members of a religion to find each other and form new, online communities is discussed in Moman 2007. (I am aware that Moman's piece has been highly controversial, but this controversy does not involve his analysis of the networking role of the Internet.) 
tablished their own independent auditing practices and did not follow the rest of the movement to the CoS stage. Ron's Org - essentially a federation of independent centers rather than a centralized organization - is a good example of a successful non-CoS Scientology organization. Founded by the aforementioned Robertson in 1984, Ron's Org is currently headquartered in Switzerland, with active centers in Switzerland, Germany, Russia and some of the CIS nations. Another spin-off organization, the Advanced Ability Center, was founded the year before in the Santa Barbara area by David Mayo and eventually sued out of existence by CoS (Reitman 2011, 157-8). In 2012, an entire Scientology center in Haifa, Israel, defected from CoS.

A somewhat different example is the Avatar Course - also known under the names Center for Creative Learning and Star's Edge International founded by Harry Palmer in 1986 (Palmer 1994). Though the group never mentions Scientology, the founder had run a Scientology franchise mission in Elmira for some ten years before starting Avatar. While groups like Ron's Org and the Haifa group adhere strictly to 'standard' Scientology, $\mathrm{CoS}$ uniformly disparages all non-CoS practitioners and groups as squirrels (Hubbard 1975, 399), a term originally applied only to practitioners who deviated from the guidelines for proper auditing.

In part because the movement was around and visible in the decades preceding the explosion of alternative spirituality in the post-sixties period, Dianetics and Scientology had a broad influence on subsequent popular therapies and spiritual groups. ${ }^{6}$ For instance, Werner Erhard based much of est (Erhard Seminar Training) on Scientology, though he never acknowledged participating in the Church (Bartley 1978, 151-2). Paul Twitchell, the founder of Eckankar, had been a staff member of the Church of Scientology, and later plagiarized some of Hubbard's writings (Lane 2008, 121-3). Additionally, Dianetics was the immediate precursor to what later became known as past-life therapy - a fact that most current past-life therapists would rather not acknowledge (Lucas 1993, 5-6). Like the Avatar Course and est, neither Eckankar nor past-life therapy are presently a part of the Free Zone, but they were nevertheless influenced by Hubbard's movement.

The CoS also licenses independent Auditors who are trained and certified to deliver Scientology 'therapy' outside of the physical boundaries of Scientology centers. Such independent Field Auditors are, in effect, single-

6 In their influential article on 'Cult Formation', Bainbridge and Stark also call attention to Scientology's disproportionate influence where they note that, 'Social Scientists studying patterns of cultural development should be aware that an occasional key organization can be an influential nexus of innovation and diffusion' $(1979,290)$. 
person Scientology franchises. As one might expect, a number of these independent Auditors have left CoS over the years and become part of the Free Zone. Though it is difficult to determine how large this phenomenon is, there are directories of independent, non-CoS Auditors online. In between organized groups like Ron's Org and individuals like Free Zone Auditors, one can also find small groups consisting of non-CoS Scientologists who meet together informally to continue their study of Scientology (as discussed in, e.g., Rubin 2011).

Movement among different Free Zone groups is relatively open, so that, for example, people not directly affiliated with Ron's Org might nevertheless seek auditing or training at a Ron's Org center. The situation would, however, be different if a 'Freezoner' approached a group like the Avatar Course/Star's Edge International, because the group has distanced itself from its origins as a Church of Scientology franchise. It should also be noted that there is some degree of tension between the people who left $\operatorname{CoS}$ in the eighties and the more recent crop of defectors. This stems in part from Robertson's claim that, after Hubbard's death, he was able to channel additional teachings from Hubbard which revealed new OT levels beyond the current eight levels taught by the Church. Though otherwise Ron's Org practitioners adhere closely to 'Standard Tech', this extraordinary claim has prompted the people who left in the twenty-first century to prefer the designation Independent Scientology - which is not really a new term - over Free Zone because of the close association of the latter term with Ron's Org.

As discussed elsewhere (e.g., Lewis 2003; 2012), new religious bodies actively seek legitimacy. One common pattern found in movement milieus is that defectors will often appeal to the authority of the founder of the primary organization, claiming that the current leadership has deviated from the founder's teachings while simultaneously asserting that they, the defectors, remain loyal to the original formulation. This is an especially common scenario in situations where schisms take place in the wake of a charismatic leader's death, such as following the death of Shrila Prabhupada, founder-leader of ISKCON (Rochford 2009). ${ }^{7}$

The Free Zone organizations and independent practitioners that acknowledge their roots in CoS embody this pattern, with the addendum that those who left the Church during the schism of 1982/3 also articulated a narrative about how Hubbard was tricked and kept in the dark during the 1980s until his death in 1986. In other words, the people who disaffili-

7 There is a brief but illuminating discussion of this pattern in Martin (2012, 121-2). 
ated claimed that the objectionable policies which drove them out of $\operatorname{CoS}$ were either issued by others in the name of the founder, or else Hubbard was being systematically misinformed and misled about what was actually happening in the Church during the period when he issued disastrous organizational policy statements. This conspiracy theory (an expression I am here using descriptively, not disparagingly) allowed defectors to reject the emergent policies put forward by $\mathrm{CoS}$ in the eighties, while continuing to claim fidelity to Hubbard's teachings. ${ }^{8}$

With the exception of the Haifa mission, the founding dates of the other organizations suggest that they all ultimately derive from the Mission Holders' schism and the subsequent shake-up of the Church of Scientology's upper management in 1982-1983. The more recent rash of defections dates from the middle of the first decade of the twenty-first century, when David Miscavige, CoS's leader after Hubbard's passing, stepped forward to take a more active role in the day-to-day running of the Church of Scientology. Because the Free Zone account of the flawed managerial decisions made in the eighties had attributed these to Hubbard's successor, the Mission Holders' Conference conspiracy theory has thus been able to come full circle to posit Miscavige as the source of both cycles of mismanagement and resulting mass defections.

When Miscavige began to assert more direct control over the running of the organization, he closed down certain offices in the Church, and sent some high-ranking officials (the ones who had not left outright) to CoS's re-education camp at Gilman Hot Springs in California. Later narratives accusing him of the physical abuse of CoS staff emerged as part of the defection stories of numerous, formerly high-ranking Church officials. These in turn led to a prominent series of exposé articles in the St. Petersburg Times that began in 2009, which then led to further negative media coverage by other news outlets and, eventually, a spate of new books in the exposé genre (e.g., Sweeney 2013; Wright 2013).

The second wave of high-level defections does not thus far seem to have generated new religious organizations beyond the Haifa mission. There is, however, an informal association of independent Scientologists that in the past five years has grown up around the blogging activities of Marty

8 Comparatively, Moman briefly discusses how the online community of former members of the Baha'i religion have reconstructed certain events - some historical; some more recent - into a self-legitimating 'apostate mythology' (2007, 202). Anyone interested in the Mission Holders' Conference and subsequent schisms should consult the latter part of Chapter Sixteen in Rathbun 2013. 
Rathbun and Steve Hall that has thus far attracted supporters composed almost entirely of people who left the Church of Scientology in recent years. Beyond mutual support and providing information about the Church, the focus of the association appears to be to initiate a reformation of $\operatorname{CoS}$ from the outside (Rathbun 2012).

\section{Discussion}

While the cultic milieu has been a handy analytic notion in our theoretical toolbox for more than four decades, there have been surprisingly few attempts to modify or extend the basic idea into related milieus. ${ }^{9}$ A core trait of most religious subcultures that seems to have thrown subsequent theoreticians off the trail is the primary organization, which generates many of the parameters of a specific movement milieu. This characteristic constitutes a significant departure from the cultic milieu, which coheres as a subculture largely because of more generic structural traits, such as the seekership ethic.

However, and unlike the cultic milieu, the traits of different movement milieus can vary considerably. Thus, for example, in the post-Prabhupada Hare Krishna milieu, some former ISKCON devotees did a complete end run around ISKCON by connecting with other teachers in Prabhupada's spiritual lineage back in India (Rochford 2009, 269-73). This kind of strategy is clearly not an option in most movement milieus.

Additionally, in his Hare Krishna Transformed, Burke Rochford drew on Fantasia and Hirsch's articulation of the notions of 'free spaces' and 'social movement havens' (1995) to discuss the oppositional social spaces created by devotees who had left or become marginal to ISKCON. This is a useful notion for discussing certain porous (discussed below) movement milieus. It is not directly applicable to an organization like CoS, which enforces a sharp boundary between committed Church members and Freezoners (i.e., there is no part of the Free Zone actually 'within' the Church of Scientology in the same sense in which other organizations contain 'free spaces').

Similarly, Eileen Barker's contribution to David Bromley's The Politics of

9 Jeffrey Kaplan and Leléne Lööw edited an anthology built around Campbell's classic piece that appeared in 2002. Contributors to this collection wrote about various movements/ subcultures that could be examined in terms of being like or as being part of the cultic milieu, with a particularly strong set of chapters on the racialist subculture. Many of the authors were top scholars who composed brilliant pieces, but few tried to think through their respective topics in terms of Campbell's notion. One notable exception was Bron Traylor's discussion of the cultic milieu and bricolage among marginalized social movements (Taylor 2002). 
Religious Apostasy (1998) contains an insightful analysis of marginal members and marginal member 'niches'. Of particular relevance for the current discussion is her discussion of the networks - which constitute a particular type of movement milieu - that emerge from associations of marginal members with peripheral members, ex-members and, in some cases, core members. Barker notes that, as these networks mature, they may even begin to publish 'Semi-underground newspapers' and, in more recent years, create Internet forums - communication networks that, as discussed by Campbell, are essential for holding together what are otherwise decentralized, anarchistic subcultures.

Fantasia and Hirsch's notion of free spaces within a movement and the notion of networks at the margins of an organization are analytically useful as ideal types, but empirical reality is messier. Such ideal types represent points in a spectrum that contains a complex variety of different possibilities. Thus, for example, Rochford's discussion of the free spaces within the Hare Krishna movement makes it clear that the phenomenon he is discussing is not contained within the movement proper but, rather, extends outside organizational boundaries entirely, and is thus quite similar to - if not actually the same as - Barker's idea of a marginal network.

Some movement milieus derive from a set of different-but-related stable primary bodies (stable in contrast to the ephemeral groups that characterize the cultic milieu) rather than from one primary body. In other words, a movement milieu can form around a group of organizations with similar ideologies and praxes that are independent from one another in the sense that they did not derive as schisms from a single original organization. Rather, an earlier historical-cultural connection has made them similar enough so that they can together set the parameters for a milieu. As noted above in my discussion of the mystery religion milieu, it is the presence of these stable organizations - acting together as a sort of distributed primary body - that makes such subcultures more than simple subsets of the cultic milieu. The Hindu Guru milieu and the Hellenistic mystery religion milieu are examples of this variant pattern. If we were to extend the astronomical metaphor, these would be referred to as binary or multiple systems.

The Scientology Free Zone is instructive because of the variety of different secondary organizations that spun off of the original CoS, from small informal groups to larger, structured organizations. In this particular milieu, secondary groups seek to establish their legitimacy by appealing to the primary's original teachings which, they claim, have been corrupted by Hubbard's organizational successors. The Avatar Course represents a 
very different kind of response, one that attempts to make a new start by repackaging the basic Scientology system and distancing itself from its origins in the Church of Scientology - thus removing itself from the Free Zone subculture entirely.

Even without disguising their origins, secondary organizations can grow and recruit substantial numbers of new members who were never participants in the original primary group. Thus, for example, Ron's Org currently has a stable base of European members, the majority of whom were never CoS Scientologists - though the original Ron's Org members were almost exclusively ex-CoS. Secondary organizations also occasionally enjoy substantial success in terms of numbers of new participants, to the point where they challenge and are able to grow beyond their primary. The Art of Living Foundation, for example, has overtaken the TM organization in terms of numbers of followers. (Tøllefsen 2011.)

Whereas the original cultic milieu's network of communications as described by Campbell was maintained by subcultural magazines, newsletters, informal meetings and the like, communication networks within contemporary movement milieus have come to be dominated by the various means of communication available on the Internet. The extent of Internet penetration varies, with some milieus maintaining the more traditional modes of communication mentioned by Campbell alongside the Internet. Other subcultures, such as the Satanic milieu, are, with some notable exceptions, almost entirely Internet milieus.

It should also be pointed out that some milieus are more porous than others. By porous, I mean fluid boundaries so that participants cross with little or no difficulty from one group to another. Some individuals might even participate in several groups simultaneously. Thus within what was earlier designated as the Hindu guru milieu, one can pass comparatively easily from TM to, for example, the SYDA Foundation or the Sivananda Yoga Vedanta Organization. Other milieus are less porous. The larger Scientology world is a striking admixture of porous and extreme non-porous - a subculture that allows relatively easy passage within the Free Zone proper, but which also erects a rigid barrier between the Church of Scientology and independent Scientologists.

In some subcultures, members of the primary body actively participate in the milieu and interact with ex-members, participants who were never members of the primary and members of secondary bodies. In many other spiritual subcultures, there is little or no participation by members of the primary body. And in the case of the Free Zone, the CoS's only participation 
has been as a hostile critic and a propagator of 'black propaganda' (Hubbard 1986 [1976], 47) against ex-members and secondary organizations.

\section{Conclusion}

Some researchers prefer seeing their analyses placed into structured outlines. Other, perhaps wiser, academicians prefer to leave their analyses in the form of ordinary discussions that better reflect the less-than-crisp nature of the empirical world. As I have gotten older I have become one of the former, despite the fact that I never cared for exercises like sentence diagramming and such when I was a public school student.

The following outline presents a list of possible characteristics rather than a model in the proper sense. Some movement subcultures will have only a handful of these traits. So with the caveat that this brief overview of the characteristics of movement milieus is provisional rather than definitive, the following is a preliminary outline:

- Primary Organization - Movement milieus tend to arise out of primary organizations that set the parameters for the larger milieu.

- Secondary Organizations - The primary body often generates secondary organizations that schism off from the primary. Secondary groups can subsequently recruit participants who are not ex-members of the primary.

- Emergent Organizational Sequences-Secondary organizations can, in turn, become primaries for yet other, newer tertiary groups and emergent sub milieus.

- Milieus Lacking a Primary Body -Alternately, some movement milieus emerge around a cluster of similar, stable organizations that, while not schisms from each another, act together to set the parameters for the milieu.

- Innovation vs. Primary Legitimacy - Former members of the primary can create innovative new secondary groups or, alternately, create secondary groups that claim to be the bearers of the primary organization's unadulterated, original teachings.

- Free Spaces - Organizations within a given milieu sometimes contain free spaces/social movement havens within which group members and/ or independents can interact outside of the hegemony of organizational authorities. These free spaces often spill over into the relevant movement milieu.

- Porousness - With some exceptions, movement milieus tend to be rela- 
tively porous subcultures within which individual participants - seekers, dabblers, marginal members and ex-members - can circulate. There are also a few milieus in which it is possible for different organizations to socialize and work together.

- Communication - Like Campbell's cultic milieu, movement milieus are held together by publications and by other sorts of communication networks. The chief difference from Campbell is that nowadays the primary vehicle for communication tends to be the Internet.

As with many typologies, and like the cultic milieu itself, the notion of a movement milieu is a heuristic device, useful for certain kinds of analyses but not for others. The above outline should be regarded as my provisional field notes, and not solidified into a 'movement milieu model' to be reproduced in course readers and memorized for exams. Hopefully, future researchers will revamp this into a more adequate schema, plus add more examples with additional empirical content.

\section{Acknowledgements:}

Though it has often been said that scholarship is a cooperative endeavor, I become more acutely aware of this fact with every passing year. In addition to the thinkers and researchers to whom I refer in the body of this article, a special word of thanks to the people who took the time to comment upon earlier drafts: Sean Currie, Asbjørn Dyrendal, Cynthia Humes, Jesper Aagaard Petersen, Murphy Pizza, Burke Rochford, Elena Vencova, Temenos' anonymous reviewers and my colleagues at the University of Tromsø. Finally, I am deeply in the debt of Chuck Beatty, himself a former long-term member of the Church of Scientology, who has patiently written me many lengthy emails explaining details about the Church's elaborate organizational and spiritual counseling structures, as well as details about both waves of defections. 
Bibliography

Atack, Jon

1990 A Piece of Blue Sky. Scientology, Dianetics and L. Ron Hubbard Exposed. New York: Lyle Stuart Books.

Bainbridge, William Sims \& Rodney Stark

1979 Cult Formation: Three Compatible Models. - Sociological Analysis 40 (4), 283-95.

1980 Client and Audience Cults in America. - Sociological Analysis 41 (3), 199-214.

\section{Barker, Eileen}

1998 Standing at the Cross-Roads. The Politics of Marginality in 'Subversive Organizations.' - David G. Bromley (ed.) The Politics of Religious Apostasy. The Role of Apostates in the Transformation of Religious Movements, 75-93. Westport, CT: Praeger Publishers.

\section{Bartley, William Warren}

1978 Werner Erhard. The Transformation of a Man, The Founding of EST. New York: Clarkson Potter

\section{Bromley, David G.}

1998 The Politics of Religious Apostasy. The Role of Apostates in the Transformation of Religious Movements. Westport, CT: Praeger Publishers.

\section{Campbell, Colin}

2002 [1972] The Cult, the Cultic Milieu, and Secularization. - Jeffrey Kaplan \& Leléne Lööw (eds), The Cultic Milieu. Oppositional Subcultures in an Age of Globalization, 12-25. Walnut Creek, CA: AltaMira Press.

\section{Fantasia, Rick \& Eric L. Hirsch}

1995 Culture in Rebellion. The Appropriation and Transformation of the Veil in the Algerian Revolution. - Hank Johnston \& Bert Klandermans (eds), Social Movements and Culture, 144-59. Minneapolis: University of Minnesota Press.

\section{Hammer, Olav}

2009 Schism and Consolidation. The Case of the Theosophical Movement. - James R. Lewis \& Sarah Lewis (eds), Sacred Schisms: How Religions Divide, 196-217. Cambridge: Cambridge University Press.

\section{Hubbard, L. Ron}

2007 [1950] Dianetics. The Modern Science of Mental Health. Commerce, California: Bridge Publications Inc.

1975 Dianetics and Scientology Technical Dictionary. Los Angeles: Church of Scientology of California Publications Organization.

1986 Modern Management Technology Defined: Hubbard Dictionary of Administration and Management. Los Angeles: Bridge Publications. Originally Published 1976. 


\section{Humes, Cynthia Ann}

2009 Schisms within Hindu Guru Groups. The Transcendental Meditation Movement in North America. - James R. Lewis \& Sarah Lewis (eds), Sacred Schisms: How Religions Divide, 287-305. Cambridge: Cambridge University Press.

2013 Personal communication with author.

Lane, David Christopher

2008 Eckankar. - Eugene V. Gallagher \& W. Michael Ashcraft (eds), Introduction to New and Alternative Religions in America, Vol. 3, 113-31. Westport, Connecticut: Greenwood Press.

\section{Lewis, James $\mathbf{R}$.}

2003 Legitimating New Religions. Piscataway, NJ: Rutgers University Press.

2007 The Pagan Explosion. - Hannah E. Johnston \& Peg Aloi (eds), The New Generation Witches. Teenage Witchcraft in Contemporary Culture, 13-24. Aldershot: Ashgate.

2010 The Science Canopy: Religion, Legitimacy, and the Charisma of Science. - Temenos. Nordic Journal for the Study of Religion 46 (1), 7-29.

2012 Excavating Tradition. Alternative Archaeologies as Legitimation Strategies. - Numen: International Review for the History of Religions 59, 202-21.

2014 Scientology: Sect, Science, or Scam? - Olav Hammer \& Timothy Jensen (eds), Religion and Identity Politics. Leiden: Brill, Forthcoming.

\section{Lewis, James R. \& Sarah Lewis (eds)}

2009 Sacred Schisms. How Religions Divide. Cambridge, UK: Cambridge University Press.

\section{Lofland, John \& Rodney Stark}

1965 Becoming a World-Saver. - American Sociological Review 30, 862-75.

\section{Lucas, Winafred Blake}

1993 Regression Therapy: A Handbook for Professionals, Vol. I. Crest Park, California: Deep Forest Press.

\section{Martin, Craig}

2012 A Critical Introduction to the Study of Religion. Sheffield, UK: Equinox.

\section{Momen, Moojan}

2007 Marginality and Apostasy in the Baha'i Community. - Religion 17, 187-209.

\section{Palmer, Harry}

1994 Living Deliberately. The Discovery and Development of Avatar. Altamonte Springs, Florida: Star's Edge International.

\section{Partridge, Christopher}

2006 The Re-Enchantment of the West. Alternative Spiritualities, Sacralization, Popular Culture and Occulture. London: T. \& T. Clark Publishers. 


\section{Petersen, Jesper A.}

2009 Satanists and Nuts. The Role of Schisms in Modern Satanism. - James R. Lewis \& Sarah Lewis (eds), Sacred Schisms. How Religions Divide, 218-47. Cambridge: Cambridge University Press.

\section{Pizza, Murphy}

2009 Schism as Midwife. How Conflict Aided the Birth of a Contemporary Pagan Community. - James R. Lewis \& Sarah Lewis (eds), Sacred Schisms: How Religions Divide, 248-61. Cambridge: Cambridge University Press.

\section{Possamai, Adam}

2007 Producing and Consuming New Age Spirituality. The Cultic Milieu and the Network Paradigm. - Daren Kemp \& James R. Lewis (eds), Handbook of New Age. Leiden: Brill, 151-65.

\section{Rathbun, Mark}

2012 The Scientology Reformation. CreateSpace Independent Publishing Platform.

2013 Memoirs of a Scientology Warrior. CreateSpace Independent Publishing Platform.

\section{Reitman, Janet}

2011 Inside Scientology. The Story of America's Most Secretive Religion. New York: Houghton Mifflin Harcourt.

\section{Richardson, James T.}

1978 Conversion careers. In and out of the new religions. Thousand Oaks: Sage Publications.

1980 Conversion Careers. - Society 17 (3), 47-50.

\section{Rochford, E. Burke}

2007 Hare Krishna Transformed. New York: NYU Press, 2007.

2009 Succession, Religious Switching, and Schism in the Hare Krishna Movement. - James R. Lewis \& Sarah Lewis (eds), Sacred Schisms. How Religions Divide, 265-86. Cambridge: Cambridge University Press.

\section{Rothstein, Mikael}

2009 'His name was Xenu, He used renegades.' Aspects of Scientology's Founding Myth. - James R. Lewis (ed.), Scientology, 365-87. New York: Oxford University Press.

\section{Rubin, Elisabeth Tuxen}

2011 Disaffiliation Among Scientologists. A Sociological Study of Post Apostasy Behaviour and Attitudes. - International Journal for the Study of New Religions 2 (2), 201-24.

\section{Seiwert, Hubert Michael}

2003 Popular Religious Movements and Heterodox Sects in Chinese History. Leiden: Brill. 


\section{Stark, Rodney}

2003 [1996] Why Religious Movements Succeed or Fail. A Revised General Model. - Lorne L. Dawson (ed.) Cults and New Religious Movements. A Reader, 259-70. Malden, MA: Blackwell Publishing.

\section{Stark, Rodney \& Roger Finke}

2000 Acts of Faith. Explaining the Human Side of Religion. Berkeley: University of California Press.

\section{Sweeney, John}

2013 The Church of Fear. Inside the Weird World of Scientology. London: Silvertail Books.

\section{Taylor, Bron}

2002 Diggers, Wolves, Ents, Elves and Expanding Universes: Bricolage, Religion, and Violence from Earth First! And the Earth Liberation Front to the Antiglobalization Resistance. - Jeffrey Kaplan \& Leléne Lööw (eds), The Cultic Milieu. Oppositional Subcultures in an Age of Globalization, 26-74. Walnut Creek, CA: AltaMira Press.

\section{Townsend, Eric}

1985 The Sad Tale of Scientology. A Short History 1950-1985. Cheshire, England: Anima Publishing.

\section{Tøllefsen, Inga Bårdsen}

2011 Art of Living: Religious Entrepreneurship and Legitimation Strategies. - International Journal for the Study of New Religions 2 (2), 255-79.

\section{Urban, Hugh B.}

2011 The Church of Scientology. A History of a New Religion. Princeton: Princeton University Press.

\section{Wallis, Roy}

1976 The Road to Total Freedom. A Sociological Analysis of Scientology. New York: Columbia University Press.

1979 Salvation and Protest. Studies of Social and Religious Movements. New York: St. Martin's Press.

\section{Wansbrough, John}

2006 [1978] The Sectarian Milieu. Content And Composition of Islamic Salvation History. Amherst, NY: Prometheus Books.

\section{Whitehead, Harriet}

1987 Renunciation and Reformulation. A Study of Conversion in an American Sect. Ithaca: Cornell University Press.

\section{Williamson, Lola}

2010 Transcendent in America. Hindu-Inspired Meditation Movements as New Religion. New York: New York University Press. 


\section{Willms, Gerald}

2009 Scientology. 'Modern Religion' or 'Religion of Modernity'? - James R. Lewis (ed.), Scientology, 245-65. New York: Oxford University Press.

\section{Wright, Lawrence}

2013 Going Clear. Scientology, Hollywood, \& the Prison of Belief. New York: Alfred A. Knopf. 